\title{
Chemiluminescent Enzyme Immunoassay for Measuring Leptin
}

\author{
Satoshi Sekiguchi, ${ }^{1,2}$ Hideki Kohno, ${ }^{2}$ Kiyoshi Yasukawa, ${ }^{1}$ and Kuniyo Inouye ${ }^{1, \dagger}$ \\ ${ }^{1}$ Division of Food Science and Biotechnology, Graduate School of Agriculture, Kyoto University, \\ Sakyo-ku, Kyoto 606-8502, Japan \\ ${ }^{2}$ Department of Applied Molecular Chemistry, College of Industrial Technology, Nihon University, \\ 1-2-1 Izumi-cho, Narashino, Chiba 275-8575, Japan
}

Received December 13, 2010; Accepted January 15, 2011; Online Publication, April 22, 2011

[doi:10.1271/bbb.100885]

Leptin is one of the representative adipocyte-derived protein hormones. Measuring the serum leptin concentration gives an important index for preventing and treating diabetes mellitus and other diseases. We constructed in this study a chemiluminescent enzyme immunoassay (CLEIA) for measuring leptin by using the anti-leptin polyclonal antibody and alkaline phosphatase (ALP). The method applies the IgG-conjugated ferrite particle to capture leptin in a sample and the ALP-conjugated Fab fragment to detect the captured leptin. We tested Block ace, CE510, and bovine serum albumin (BSA) for their abilities to block non-specific binding of ALP-conjugated anti-leptin Fab to the ferrite particle and found BSA to be the most effective. The measurable range with this ELISA for leptin was 0.1$1.0 \mathrm{pg} / \mathrm{mL}$ of leptin and the detection limit (blank + 2SD) was $0.1 \mathrm{pg} / \mathrm{mL}$ of leptin. These results demonstrate sufficient sensitivity with our system to measure the serum leptin concentration and its clinical usefulness. The results also suggest that a sensitive enzyme immunoassay can be constructed by using only one polyclonal antibody.

Key words: alkaline phosphatase; bovine serum albumin; chemiluminescent enzyme immunoassay; leptin; polyclonal antibody

Leptin is one of the representative adipocyte-derived protein hormones. It was identified in 1994 as an $o b$ gene product of the obesity and insulin-resistant $o b / o b$ mouse model. ${ }^{1)}$ It is involved in energy homeostasis and insulin resistance via its central effect on the hypothalamus and peripheral effect on fatty acid oxidation, and is considered to primarily serve as a signal of sufficient energy for the human body. ${ }^{2)}$ The leptin level decreases when an individual receives less nutrition and loses weight; and the appetite is concomitantly increased and the energy expenditure therefore decreased through a mechanism of physiological adaptation. ${ }^{2-5)}$ The leptin deficiency in $o b / o b$ mice is associated with hyperinsulinemia and insulin resistance which can be corrected by an exogenous administration of leptin before the development of persistent obesity. ${ }^{6,7)}$ However, the situation observed with humans is largely different from that with $o b / o b$ mice; in most human cases, a high leptin level often accompanies obesity, suggesting leptin resistance in humans. The leptin level in humans is directly correlated with the adipose tissue mass as well as the nutritional status. ${ }^{8-11)}$

An immunological reaction using antibodies is widely applied to assay various biological materials, because it is highly specific and rapid. An immunoassay has been the key technique for clinical diagnoses and biological analyses, particularly since the development of monoclonal antibodies. ${ }^{12)}$ It is essential to quickly and precisely identify the stage of the disorder to effectively treat a patient.

A light-emitting chemical reaction (chemiluminescence) produces electromagnetic radiation. The combination of an enzyme and chemiluminescence in the chemiluminescent enzyme immunoassay (CLEIA) provides a highly sensitive analytical method. The enzyme and substrate currently most extensively used for CLEIA are alkaline phosphatase (ALP) and a 3-(2'-spiroadamantane)-4-methoxy-4-( $3^{\prime \prime}$-phosphoryloxy)phenyl-1,2dioxetane disodium salt (AMPPD). ${ }^{13)}$ ALP (EC 3.1.3.1) is a homodimeric metalloenzyme that catalyzes the hydrolysis of phosphomonoesters, whose subunit (about $50 \mathrm{kDa}$ ) contains two $\mathrm{Zn}^{2+}$ ions and one $\mathrm{Mg}^{2+}$ ion. ${ }^{14-16)}$ The concentration of the enzyme-reaction product formed in a particular reaction time (an end-point assay) or the reaction velocity for product formation (a rate assay) is measured by using the change in luminescence.

Measuring the serum leptin concentration gives an important index for preventing and treating diabetes. A highly sensitive EIA procedure is required because the serum leptin concentration is very low $(<10 \mathrm{ng} / \mathrm{mL}$ for a normal individual). We constructed in this study a CLEIA method for measuring leptin that meets such a criterium.

\section{Materials and Methods}

Materials. Recombinant human leptin expressed in Escherichia coli (lot no. 115K1687), pepsin from porcine stomach mucosa, horseradish peroxidase-conjugated goat anti-rabbit IgG (lot no. 125K6059), and bovine serum albumin (BSA) were purchased from Sigma (St. Louis, MO, USA). Magnetic carboxyl-modified ferrite particles were from Nippon Paint Co. (Tokyo, Japan), and $\mathrm{N}$-hydroxysuccinimide (NHS) was from Kanto Chemicals (Tokyo, Japan). o-Phenylenediamine dihydrochloride (OPD) and 1-ethyl-3-(3-dimethylaminopropyl)-carbo-

$\dagger$ To whom correspondence should be addressed. Tel: +81-75-753-6266; E-mail: inouye@kais.kyoto-u.ac.jp

Abbreviations: AMPPD, adamantly 1,2-dioxetanephenyl phosphate; ALP, alkaline phosphatase; CLEIA, chemiluminescent enzyme immunoassay; EIA, enzyme immunoassay; HRP, horseradish peroxidase; MES, 2-( $N$-morpholino)ethanesulfonic acid; OPD, $o$-phenylenediamine dihydrochloride 
diimide hydrochloride were from Wako Pure Chemicals (Osaka, Japan). Block ace was from Snow Brand Milk Products Co. (Tokyo, Japan) and CE510 was from JSR Corporation (Tokyo, Japan). All other chemicals were of reagent grade and purchased from Nacalai Tesque (Kyoto, Japan) and Wako Pure Chemicals.

Preparation of the polyclonal antibody. The rabbit anti-leptin polyclonal antibody was prepared in accordance with the conventional procedure. ${ }^{17,18)}$ Rabbits (Japanese White) were initially immunized with $1 \mathrm{mg}$ of recombinant human leptin in Freund's complete adjuvant and then with $0.5 \mathrm{mg}$ of leptin in Freund's incomplete adjuvant for all subsequent injections at 1 week intervals. Antibodies in the serum were detected in 96-well microplates that had been coated with leptin $(100 \mu \mathrm{L}$ of $5 \mu \mathrm{g} / \mathrm{mL}$ in $0.1 \mathrm{M}$ sodium carbonate at $\mathrm{pH} 9.6)$ and then blocked with 5\% skim milk (Difco, Detroit, MI, USA) in $10 \mathrm{~mm}$ phosphate-buffered saline (PBS) at $\mathrm{pH}$ 7.4. The plates were washed with $10 \mathrm{~mm}$ PBS (pH 7.4) containing $0.05 \%$ Tween 20 . Sera of varying dilution were added to each well, and the reaction mixture then incubated at room temperature for $1 \mathrm{~h}$. After washing three times with $10 \mathrm{~mm}$ PBS (pH 7.4) containing $0.05 \%$ Tween 20, the bound antibodies were detected by sequentially incubating with HRP-conjugated goat anti-rabbit IgG $(100 \mu \mathrm{L}$ of a 6000 -fold diluent in PBS) and OPD $(100 \mu \mathrm{L}$ of $0.4 \mu \mathrm{g} / \mathrm{mL}$ in $10 \mathrm{~mm}$ PBS at $\mathrm{pH} 7.4)$.

IgG was purified from the sera of immunized rabbits as previously described. ${ }^{19,20)}$ The collected sera were centrifuged at $10,000 \times g$ for $15 \mathrm{~min}$ to collect the supernatant. Solid ammonium sulfate was added to give $50 \%$ saturation. The precipitate was collected by centrifugation at $10,000 \times g$ for $10 \mathrm{~min}$, dissolved in $3 \mathrm{~mL}$ of $10 \mathrm{mM}$ PBS ( $\mathrm{pH} \mathrm{7.4),} \mathrm{and}$ dialyzed overnight against $20 \mathrm{~mm}$ PBS ( $\mathrm{pH} 7.4$ ). The dialysate was passed through a $0.45-\mu \mathrm{m}$ filter and applied to a $1-\mathrm{mL}$ Protein A column (GE Healthcare, Buckinghamshire, UK) that had been equilibrated with $20 \mathrm{~mm}$ PBS at pH 7.4. The column was washed with $20 \mathrm{~mm}$ PBS ( $\mathrm{pH} 7.4$ ), and $\mathrm{IgG}$ was eluted with $0.1 \mathrm{M}$ citrate- $\mathrm{NaOH}(\mathrm{pH} 3.0)$ at a flow rate of $0.3 \mathrm{~mL} / \mathrm{min}$ at room temperature. The fractions were collected and dialyzed overnight against $10 \mathrm{~mm}$ PBS (pH 7.4). The concentration of purified $\mathrm{IgG}$ was spectrophotometrically determined by using an absorption of 1.4 at $280 \mathrm{~nm}\left(A_{280}\right)$ for a concentration of $1.0 \mathrm{mg} / \mathrm{mL}$ and a molecular mass of $150 \mathrm{kDa}$ for $\operatorname{IgG} .{ }^{17-20)}$

Preparation of the $F\left(a b^{\prime}\right)_{2}$ fragment. The $\mathrm{F}\left(\mathrm{ab}^{\prime}\right)_{2}$ fragment was prepared as previously described. $\left.{ }^{21,22}\right)$ Purified $\mathrm{IgG}(2.0 \mathrm{~mL}$ of 4.0 $\mathrm{mg} / \mathrm{mL}$ ) was dialyzed overnight against $0.1 \mathrm{M}$ citrate- $\mathrm{NaOH}(\mathrm{pH} 3.5)$. A pepsin solution $(40 \mu \mathrm{L}$ of $1.0 \mathrm{mg} / \mathrm{mL}$ in $0.1 \mathrm{M}$ citrate- $\mathrm{NaOH}$ $(\mathrm{pH} 3.5))$ was added to the dialyzate, and the mixture incubated at $37^{\circ} \mathrm{C}$ for $2 \mathrm{~h}$. This mixture contained 7 units of pepsin to $1 \mathrm{mg}$ of $\mathrm{IgG}$, giving a pepsin to $\mathrm{IgG}$ ratio of 1:50 (w/w). The reaction was stopped by adjusting the $\mathrm{pH}$ value of the reaction mixture to 7.4 by adding $3 \mathrm{M}$ Tris. The mixture was then dialyzed overnight against $10 \mathrm{~mm}$ PBS $(\mathrm{pH} 7.4)$ at $4{ }^{\circ} \mathrm{C}$. The resulting dialyzate was applied to a Superdex 200 column $(10 \mathrm{~mm}$ i.d. $\times 600 \mathrm{~mm})$ that had been equilibrated with $10 \mathrm{~mm}$ PBS at pH 7.4 and eluted at a flow rate of $0.33 \mathrm{~mL} / \mathrm{min}$ at $4{ }^{\circ} \mathrm{C}$. The fractions containing the $\mathrm{F}\left(\mathrm{ab}^{\prime}\right)_{2}$ fragments were collected and stored at $4{ }^{\circ} \mathrm{C}$ before being used. The protein concentration was determined with a BCA protein assay kit (Pierce, IL, USA), using with BSA as the standard.

Preparation of the ALP-conjugated Fab fragment. The ALPconjugated Fab fragment was prepared from ALP and the $F\left(\mathrm{ab}^{\prime}\right)_{2}$ fragment by using an SH alkaline phosphatase labeling kit (Dojindo, Kumamoto, Japan) and stored at $4{ }^{\circ} \mathrm{C}$ before being used. The protein concentration was determined with a BCA protein assay kit, using BSA as the standard.

Preparation of the IgG-conjugated ferrite particles. The carboxyl group of the magnetic carboxyl-modified ferrite particles was activated by mixing the ferrite particles $(2.0 \mathrm{~mL}$ of $2.5 \mathrm{mg} / \mathrm{mL}$ in $50 \mathrm{mM}$ MES$\mathrm{NaOH}(\mathrm{pH} 5.6))$, NHS $(230 \mu \mathrm{L}$ of $50 \mathrm{mg} / \mathrm{mL}$ in $50 \mathrm{~mm} \mathrm{MES-NaOH}$ (pH 5.6)), and the water-soluble carbodiimide, 1-ethyl-3-(3-dimethylaminopropyl)-carbodiimide hydrochloride $(2.0 \mathrm{~mL}$ of $20 \mathrm{mg} / \mathrm{mL}$ in a $50 \mathrm{~mm}$ MES-NaOH buffer ( $\mathrm{pH}$ 5.6)) and then incubating the mixture at $25^{\circ} \mathrm{C}$ for $30 \mathrm{~min}$ while continuously stirring. The mixture was centrifuged at $10,000 \times g$ for $7 \mathrm{~min}$, before the particles were washed twice with the same buffer and re-suspended in this same buffer.
IgG was conjugated with the modified particles by mixing the particles $(1.97 \mathrm{~mL}$ of $2.5 \mathrm{mg} / \mathrm{mL}$ in $50 \mathrm{~mm} \mathrm{MES}-\mathrm{NaOH}(\mathrm{pH} \mathrm{5.6)})$ and $\operatorname{IgG}(30 \mu \mathrm{L}$ of $2.0 \mathrm{mg} / \mathrm{mL}$ in $10 \mathrm{~mm}$ PBS $(\mathrm{pH} 7.4))$ and incubating the mixture at $37^{\circ} \mathrm{C}$ for $30 \mathrm{~min}$ while continuously stirring. The mixture was finally centrifuged at $22,600 \times g$ for 7 min to collect the precipitate of IgG-conjugated ferrite particles.

Thermal treatment of BSA. BSA ( $2 \mathrm{~g})$ was added to $100 \mathrm{~mm}$ glycine$\mathrm{NaOH}, 0.15 \mathrm{M} \mathrm{NaCl}, 5 \mathrm{~mm}$ EDTA and $0.1 \% \mathrm{w} / \mathrm{v} \mathrm{NaN}_{3}$ (pH 9.6), and topped up to $200 \mathrm{~mL}$. The mixture was incubated at $55^{\circ} \mathrm{C}$ for $20 \mathrm{~min}$ and then immediately cooled to room temperature.

Test of the blocking reagents. The IgG-conjugated ferrite particles $(5 \mathrm{mg})$ were dispersed in $1.0 \mathrm{~mL}$ of $50 \mathrm{~mm}$ MES-NaOH $(\mathrm{pH} 7.6)$. One $\mathrm{mL}$ of a $1 \%$ blocking reagent (Block ace, CE510, or BSA) was added and allowed to react at $25^{\circ} \mathrm{C}$ for $30 \mathrm{~min}$ while continuously stirring. The particles were washed with $0.1 \mathrm{M}$ Tris- $\mathrm{HCl}(\mathrm{pH} 8.2)$ and finally suspended in the same buffer. Measurements were taken with a Lumipulse $f$ fully automatic CLEIA system (Fujirebio, Tokyo), using $1.5 \mu \mathrm{g} / \mathrm{mL}$ of the antibody-conjugated ferrite particles and $50 \mathrm{ng} / \mathrm{mL}$ of ALP-Fab.

Standard CLEIA curve for leptin. Stock solutions of leptin were diluted with the standard matrix (Fujirebio) to $0.1-1.0 \mathrm{pg} / \mathrm{mL}$. Measurements were taken with the Lumipulse $f$ as just described above.

\section{Results}

\section{CLEIA construction for leptin}

Figure 1 shows a schematic representation of CLEIA for leptin comprising IgG-conjugated ferrite particles for capturing leptin in a sample and the ALP-conjugated Fab fragment for detecting the captured leptin. Chemiluminescence was detected at $477 \mathrm{~nm}$ which was emitted from the product by the ALP reaction with AMPPD as a substrate. CLEIA for leptin was conducted by the following procedure: (i) rabbits were immunized with leptin or CRP; (ii) IgG was purified by the sera of the immunized rabbits; (iii) the $\mathrm{F}\left(\mathrm{ab}^{\prime}\right)_{2}$ fragment was prepared from IgG by pepsin digestion; (iv) ALP was chemically conjugated with the Fab fragment (Fig. 2A); and (v) IgG was chemically conjugated with the ferrite particles (Fig. 2B).

The rabbits were immunized with leptin. The antileptin antibody in the sera was measured by EIA, using leptin-coated microplates, as described in the Materials

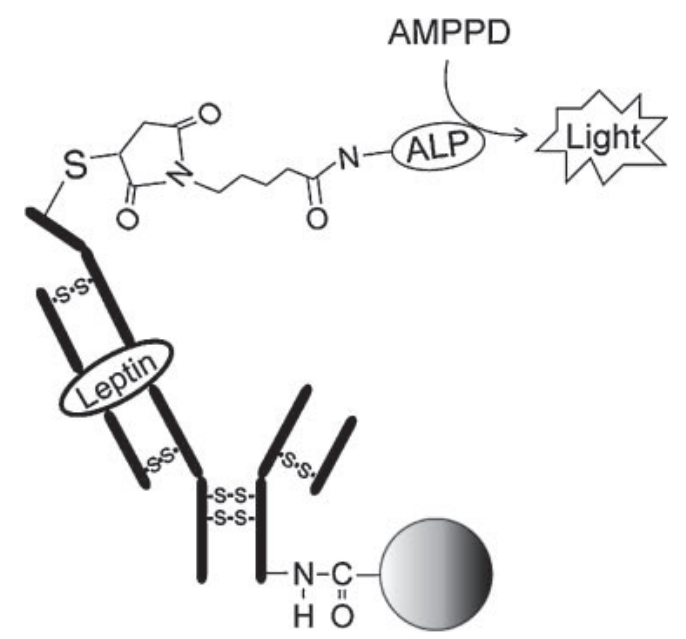

Fig. 1. Schematic Representation of the CLEIA Procedure for Leptin. 


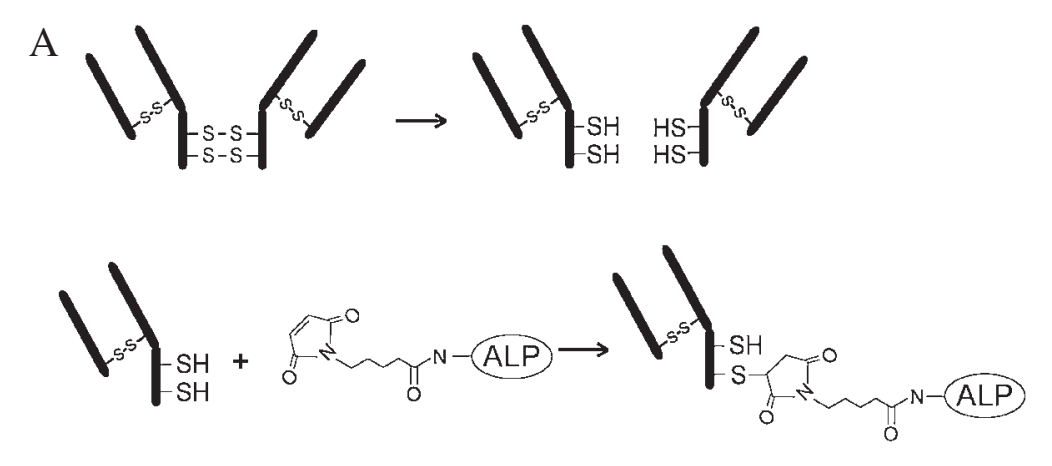

B
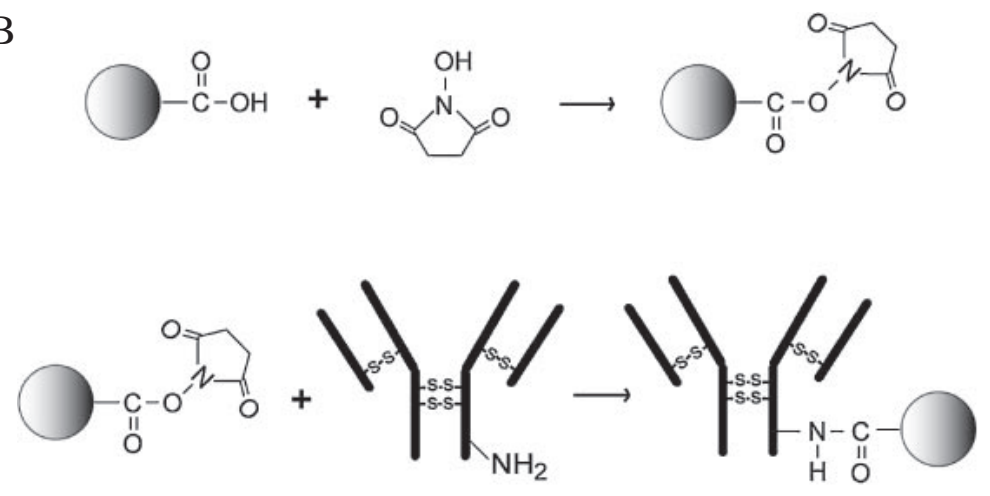

Fig. 2. Chemical Conjugation.

A, ALP to the Fab fragment; B, IgG to the ferrite particles.

and Methods section. The titer of the anti-leptin antibody in the sera reached a maximum $21 \mathrm{~d}$ after the onset of immunization. IgG was then purified from the total sera by ammonium sulfate precipitation and Protein A affinity chromatography. Figure $3 \mathrm{~A}$ shows the elution pattern for gel filtration chromatography of the purified IgG preparation. IgG was eluted almost as a single peak, and the purity was estimated to be more than $98 \%$.

The $\mathrm{F}\left(\mathrm{ab}^{\prime}\right)_{2}$ fragment was prepared from IgG by pepsin digestion and purified by gel filtration chromatography. Figure 3B shows the elution pattern for gel filtration chromatography. The $\mathrm{F}\left(\mathrm{ab}^{\prime}\right)_{2}$ fragment was eluted as the first peak, and the Fc fragment, as the second peak.

ALP was conjugated with the Fab fragment as shown in Fig. 2A. The disulfide bridges of the $F\left(a b^{\prime}\right)_{2}$ fragment connecting two Fab fragments were reduced to make the Fab fragment. The disulfide bridges connecting the heavy and light chains were not reduced in this reaction. The maleimide group was introduced to the amino group of ALP to make SH-reactive ALP. The Fab fragment and SH-reactive ALP were mixed to make the ALPconjugated Fab fragment. Figure 3C shows the elution pattern for gel filtration chromatography of the reaction mixture of SH-reactive ALP and the Fab fragment. The ALP-conjugated Fab fragment was eluted as the first peak, and the Fab fragment and ALP, as the second peak.

\section{Test of the blocking reagents}

Non-specific binding of the ALP-conjugated Fab fragment should be reduced to a minimum to achieve high sensitivity. The commercial blocking reagents, Block ace, CE510, and BSA, were each tested to block this non-specific binding. Block ace is a protein mixture prepared from milk, CE510 is a hydrophilic synthetic polymer, and BSA was treated at $55^{\circ} \mathrm{C}$ to inactivate any contaminating viruses and enzymes. We confirmed that heat-treated BSA fully retained its blocking ability. The ALP-conjugated Fab fragment which had been purified by gel filtration and that which had not (the purified and unpurified ALP-conjugated Fab fragments, respectively) were tested. Either the purified or unpurified ALPconjugated Fab fragment was mixed with the particles after the blocking reaction. Figure 4 shows the luminescence counts as BSA $<$ CE510 < Block ace. When the purified ALP-conjugated Fab fragment was used, the respective coefficient variation $(\mathrm{CV})$ values for Block ace, CE510, and BSA were 11.9, 9.6, and 5.2\% $(\mathrm{n}=8)$. The purified ALP-conjugated Fab fragment exhibited smaller counts than the unpurified fragment, so we selected BSA and the purified ALP-conjugated Fab fragment for further study.

\section{Standard curve}

Figure 5 shows the standard curve for leptin when using the Lumipulse $f$ fully automated CLEIA system (Fujirebio). The measurable range for leptin was 0.1$1.0 \mathrm{pg} / \mathrm{mL}$, and the detection limit (blank + 2SD) for leptin was $0.1 \mathrm{pg} / \mathrm{mL}$. The range of $\mathrm{CV}$ values at each point was $1.3-5.7 \%(n=6)$, and the time required for all steps was $40 \mathrm{~min}$.

\section{Discussion}

\section{Sensitivity of CLEIA for leptin}

The serum concentrations of various proteins that play important physiological roles are very low. This feature is most typical for such adipocytokines as leptin, IL-1, IL-6, resistin, and TNF- $\alpha{ }^{23-26)}$ Several EIA microtiter kits for leptin are commercially available. According to the manufacturers' instructions, the measurable ranges 
A

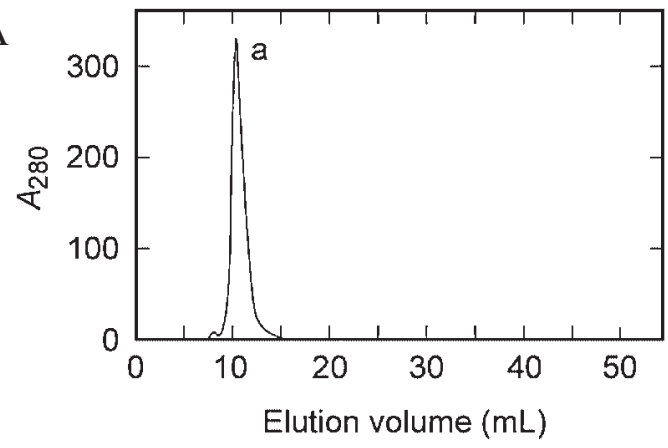

B

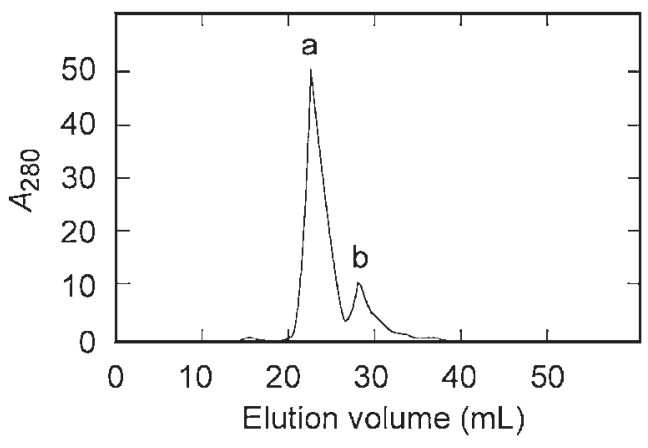

$\mathrm{C}$

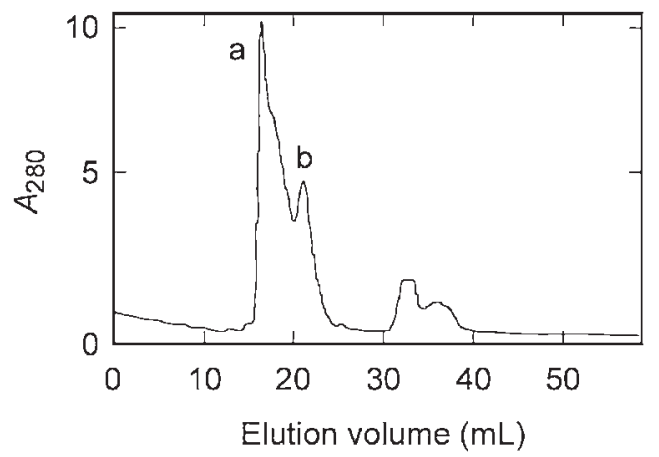

Fig. 3. Elution Patterns for Gel Filtration Chromatography with Superdex 200.

The resin was equilibrated with $10 \mathrm{~mm} \mathrm{PBS}$ at $\mathrm{pH} 7.4$, and the flow rate was $0.25 \mathrm{~mL} / \mathrm{min}$. A, IgG purified by Protein-A affinity column chromatography was applied. The main peak (a) represents IgG. B, IgG digested by pepsin was applied. The first (a) and second (b) peaks respectively represent the $\mathrm{F}\left(\mathrm{ab}^{\prime}\right)_{2}$ fragment and $\mathrm{Fc}$ fragment. C, The reaction mixture for chemical conjugation of ALP to the Fab fragment was applied. The first (a) and second (b) peaks respectively represent the ALP-conjugated Fab fragment and the mixture of ALP and the Fab fragment.

for leptin are $15.6-1000 \mathrm{pg} / \mathrm{mL}$ for the Human Leptin Immunoassay kit (Qiagen, Hamburg, Germany) and Leptin ELISA Human kit (R\&D Systems, Minneapolis, MN, USA), $1-50 \mathrm{ng} / \mathrm{mL}$ for the Human Leptin ELISA kit (B-Bridge International, Cupertino, CA, USA), and $0.5-100 \mathrm{ng} / \mathrm{mL}$ for the Human Leptin ELISA kit (Linco Research, St. Charles, MO, USA). The respective serum leptin concentrations in the healthy male and female volunteers were the range of 2.2-11.1 and 3.9-77.2 $\mathrm{ng} / \mathrm{mL}$ according to the manual for the Human Leptin Immunoassay kit. The times required for all steps were several hours.

The measurable amount with our system was 0.1$1.0 \mathrm{pg} / \mathrm{mL}$ of leptin, and the detection limit (blank + 2SD) was $0.1 \mathrm{pg} / \mathrm{mL}$ of leptin. Even if 10-100-fold dilution of the serum would be necessary for measurement, our system is sensitive enough to measure the serum leptin concentration without being affected by various substances and might thus be clinically useful for diagnosing such a disease as diabetes mellitus. We consider that high sensitivity was achieved for the following reasons: (i) CLEIA with ALP has higher performance than other immunoassays; (ii) a blocking reagent was optimized; (iii) ferrite particles to which the anti-leptin antibody was chemically conjugated, but not physically absorbed, were used; and (iv) the anti-leptin antibody, to which ALP was chemically conjugated, was used instead of a combination of the anti-leptin antibody and ALP-conjugated anti-antibody. We speculate that, of these four reasons, the high performance of CLEIA was the most critical. This should be experimentally clarified in the future. One possible strategy for further increasing the sensitivity of our system is to increase the ALP activity. In this respect, we have already reported that the synchronous enzyme reaction of ALP and alcohol dehydrogenase increased the sensitivity of EIA, ${ }^{27)}$ and recently found that aminoalcohol and polyethyleneglycol increased the ALP activity (unpublished results).

\section{Optimization of the blocking reagents}

Blocking is an important step in EIA, and it reduces non-specific binding to the solid phase. Non-specific binding of ALP-conjugated Fab to the ferrite particles triggers a high background with our system. We found that BSA, a conventional blocking reagent, was the most effective blocking reagent (Fig. 4). However, polyethyleneglycol, ${ }^{28)}$ polyvinylalcohol, ${ }^{28)}$ polyvinylpyrrolidone, ${ }^{29)}$ milk, $^{30)}$ and casein $^{30)}$ were all more effective than BSA according to previous reports. Our system involves the carboxyl group of the ferrite particles being modified with NHS, to which IgG was conjugated, the particles therefore not being charged. An antibody can be bound to the particles only through physical absorption. In this case, the carboxyl group of the particles is negatively charged under the assay conditions ( $\mathrm{pH}$ 7.4). On the other hand, BSA, whose isoelectric point is $4.7-4.8,{ }^{31)}$ is also negatively charged at $\mathrm{pH}$ 7.4. There is a possibility that an electrostatic repulsive force between the unmodified particles and BSA reduced the blocking effect of BSA in these previous studies. ${ }^{28-30)}$ Such a repulsive force does not occur in our system using IgG-conjugated particles and BSA.

\section{Use of a polyclonal antibody in EIA}

Two monoclonal antibodies that recognize different regions of a target molecule are generally used in EIA. However, we did not have an anti-leptin antibody with high affinity. Making a monoclonal antibody is often time-consuming and sometimes results in limited success when compared to making a polyclonal antibody. We hypothesized in this study that a sensitive EIA procedure for leptin could be constructed by using only one anti-leptin polyclonal antibody, and the results were satisfactory.

We have also constructed a CLEIA procedure for measuring the $\mathrm{C}$-reactive protein (CRP) by using one anti-CRP polyclonal antibody (unpublished results). When compared with the latex turbidimetric immunoassay (LTIA) for $\mathrm{CRP},{ }^{32)}$ the measurable range of 


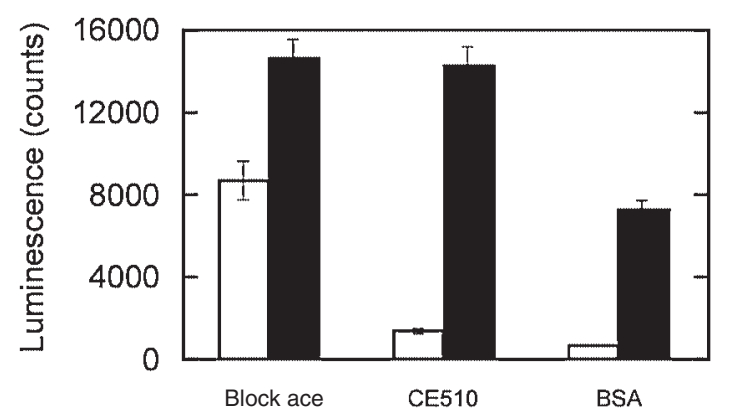

Fig. 4. Effects of Blocking Reagents on the Luminescence Count. The IgG-conjugated ferrite particles were suspended in $1 \mathrm{~mL}$ of $50 \mathrm{~mm}$ MES-NaOH (pH 5.6) containing either $0.5 \% \mathrm{w} / \mathrm{v}$ Block ace, CE510, or BSA, and the blocking reaction was carried out as described in the Materials and Methods section. The ferrite particles were then mixed with the ALP-conjugated Fab fragment which had been purified by gel filtration (unshaded column) or not (shaded column) and subsequently reacted with AMPPD as a substrate. The average of the luminescence counts $(n=8)$ is shown. Error bars indicate SD values.

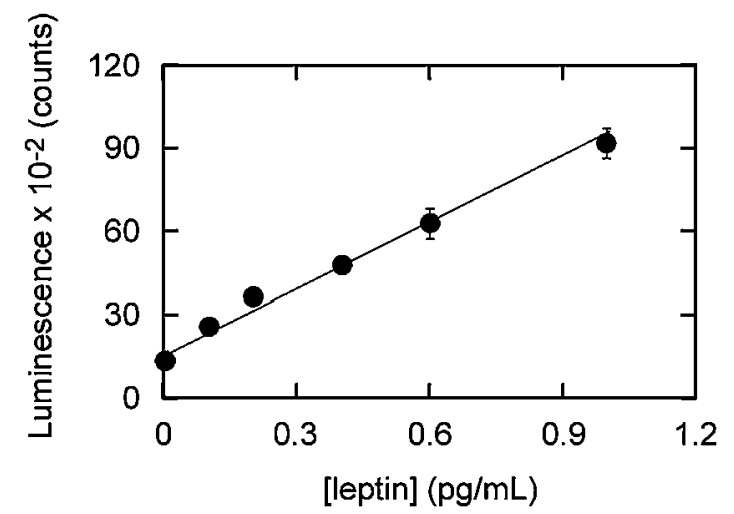

Fig. 5. Standard Curves for Leptin.

Leptin $(100 \mu \mathrm{L}$ of $0-1.0 \mathrm{pg} / \mathrm{mL})$ was used to make a standard curve. The CV values at each point were $1.3-5.7 \%(n=6)$. Error bars indicate SD values.

CLEIA for CRP was higher than that of LTIA (unpublished results). Our results for the EIA procedure using one polyclonal antibody for leptin or CRP suggest that sensitive EIA was possible when using only one polyclonal antibody. However, it should be mentioned that EIA with a monoclonal antibody is preferable to one with a polyclonal antibody in that the same polyclonal antibody cannot be consistently produced.

In conclusion, we established a highly sensitive and rapid CLEIA procedure for measuring leptin by using the fully automated Lumipulse $f$ CLEIA system to detect $0.1 \mathrm{pg} / \mathrm{mL}$ of leptin in $40 \mathrm{~min}$. This procedure is highly sensitive and rapid compared with the conventional microtiter EIA kits. Measuring the serum leptin concentration of patients with diabetes mellitus is currently underway with this system. The effects of various solvents and additives on ALP activity are also being examined to further improve the performance of this system.

\section{References}

1) Zhang Y, Proenca R, Maffei M, Barone M, Leopold L, and Friedman JM, Nature, 372, 425-432 (1994).

2) Shiomura I, Funahashi T, Takahashi M, Maeda K, Kotani K, Nakamura T, Yamashita S, Miura M, Fukuda Y, Takemura K, Tokunaga K, and Matsuzawa Y, Nat. Med., 2, 800-803 (1996).

3) Bjorbaek C and Kahn BB, Recent Prog. Horm. Res., 59, 305331 (2004).

4) Filer JS, J. Clin. Endocrinol. Metab., 83, 1407-1413 (1998).

5) Friedman JM and Halaas JL, Nature, 395, 763-770 (1998).

6) Shimomura I, Hammer RE, Ikemoto S, Brown MS, and Goldstein JL, Nature, 401, 73-76 (1999).

7) Ebihara K, Ogawa Y, Masuzaki H, Shintani M, Miyanaga F, Aizawa-Abe M, Hayashi T, Hosoda K, Inoue G, Yoshimasa Y, Gavrilova O, Reitman ML, and Nakao K, Diabetes, 50, 14401448 (2001).

8) Fain JN, Madan AK, Hiler ML, Cheema P, and Bahouth SW, Endocrinology, 145, 2273-2282 (2004).

9) Wajchenberg BL, Endocr. Rev., 21, 697-738 (2000).

10) Wajchenberg BL, Giannella-Neto D, da Silva ME, and Santos RF, Horm. Metab. Res., 34, 616-621 (2002).

11) Sotirios $\mathrm{T}$ and Christos $\mathrm{M}$, Am. J. Infect. Dis., 2, 141-152 (2006).

12) Köhler G, Hengartner H, and Shulman MJ, Eur. J. Immunol., 8, 82-88 (1978).

13) Bronstein I, Edwards B, and Voyta JC, J. Biolumin. Chemilumin., 4, 99-111 (1989).

14) Stec B, Holtz KM, and Kantrowitz ER, J. Mol. Biol., 299, 13031311 (2000).

15) De Backer MME, McSweeney S, Lindley PF, and Hough E, Acta Cryst., D60, 1555-1561 (2004).

16) Gettins P and Coleman JE, J. Biol. Chem., 258, 408-416 (1983).

17) Berlin ZB and Mckinney R, J. Lab. Clin. Med., 52, 657-658 (1958).

18) Freund J and Thompson KJ, Science, 101, 468 (1945).

19) Morimoto K and Inouye K, J. Biochem. Biophys. Methods, 24, 107-117 (1992).

20) Morimoto K and Inouye K, J. Biochem. Biophys. Methods, 26, 27-39 (1993).

21) Morimoto K and Inouye K, J. Immunol. Methods, 205, 81-90 (1997).

22) Morimoto K and Inouye K, J. Immunol. Methods, 224, 43-50 (1999).

23) Matsusawa Y, FEBS Lett., 580, 2917-2921 (2006).

24) Dostalova IM, Kunesova M, Duskova J, Papezova H, and Nedvidkova J, Nutrition, 22, 977-983 (2006).

25) Risch L, Saely C, Hoefle G, Rein P, Langer P, Gouya G, Marte T, Aczel S, and Drexel H, Clin. Chim. Acta, 376, 108-113 (2007).

26) Ashizawa N, Yahata T, Quan J, Adachi S, Yoshihara K, and Tanaka K, Gynecol. Oncol., 119, 65-69 (2010).

27) Inouye K, Ueno I, Yokoyama S, and Sakaki T, J. Biochem., 131, 97-105 (2002).

28) Nagasaki Y, Kobayashi H, Katsuyama Y, Jomura T, and Sakura T, J. Colloid Interface Sci., 309, 524-530 (2007).

29) Studentsov YY, Schiffman M, Strickler HD, Ho GYF, Pang YYS, Schiller J, Herrero R, and Burk RD, J. Clin. Microbiol., 40, 1755-1760 (2002).

30) Vogt RFJr, Phillips DL, Henderson LO, Whitfield W, and Spierto FW, J. Immunol. Methods, 101, 43-50 (1987).

31) Salaman MR and Williamson AR, Biochem. J., 122, 93-99 (1971).

32) Komoriya T, Kikuchi M, Terashima Y, Okamoto M, Ogawa M, Moriyama M, and Kohno H, Biosci. Biotechnol. Biochem., 74, 292-297 (2010). 